\title{
Time-Domain Reflectometry (TDR) in mapping soil temperature and humidity
}

\author{
Jakub Sikora ${ }^{1}$, Maciej Gliniak ${ }^{1 *}$, Urszula Sadowska ${ }^{2}$, Agnieszka Klimek-Kopyra ${ }^{3}$ and \\ Agnieszka Latawiec ${ }^{4}$ \\ ${ }^{1}$ Institute of Agricultural Engineering and Informatics, University of Agriculture in Krakow, Poland \\ ${ }^{2}$ Institute of Machinery Exploitation, Ergonomics and Production Processes, University of \\ Agriculture in Krakow, Poland \\ ${ }^{3}$ Institute of Plant Production, Faculty of Agriculture and Economy, University of Agriculture in \\ Krakow, Poland \\ ${ }^{4}$ Department of Production Organization, Logistics and Applied Computer Science, University of \\ Agriculture in Krakow, Poland
}

\begin{abstract}
The article presents the possibilities of using time-domain reflectometry (TDR) to determine the temperature and moisture content of mineral soil. The TDR method is based on measuring the time of an electromagnetic impulse's flow between the source and the obstacle. The reflected signal contains information about the dielectric properties of the tested material, allowing to determine the qualitative and quantitative properties of the material. The tests in question were carried out using a mobile reflectometric device as an electronic temperature and humidity meter. On the basis of the obtained results, the usefulness of reflectometric methods in the study of the temperature and moisture content of mineral soil was determined.
\end{abstract}

\section{Introduction}

Knowledge of soil temperature and the content and distribution of water in the root zone of plants is of paramount importance for soil-related disciplines, such as soil science, agriculture, forestry and hydrology. In recent years [31], domain-time reflectometry (TDR) has become a popular method of rapid and non-destructive measurement of apparent soil dielectric permittivity, which is associated with soil water volume content, temperature and electrical conductivity [1-5, 28-30]. Currently, advanced TDR devices are used to measure the water level in Mariotte tubes [6], to estimate the water potential in soil [7] or conductivity of a soil water solution [8].

Due to the problem of changes in soil sample moisture in transport, research on the use of electrical and electro-magnetic properties of soil for testing temperature and current humidity has been ongoing for many years [9-14].

Time-domain reflectometry is an electro-magnetic measuring technique used to determine the electrical conductivity of materials - dielectric and spectroscopic properties of materials [15-18]; qualitative and quantitative control of liquids [19-21]; examinations of 
vegetable oils [22-24]; cable fault detection [23-26]; and measurement of soil moisture [2527]. The method uses special bipolar probes, which measure the time of an electrical impulse flow between the electrodes of the probe in a water solution. The probe consists of two electrically connected waveguides, concentric and parallel (formed by two parallel metal rods). An initial pin impulse of voltage with a fixed rise and fall time runs from the generator towards the sensor. The recorder records its course when the impulse passes the divider. The measurement results are recorded as a waveform, demonstrating the relationship between the time of the electrical pulse flow and the length and distance of the electrodes in the probe (Fig. 1). Based on the above, the bulk electrical permittivity is determined $[8,12,15]$.

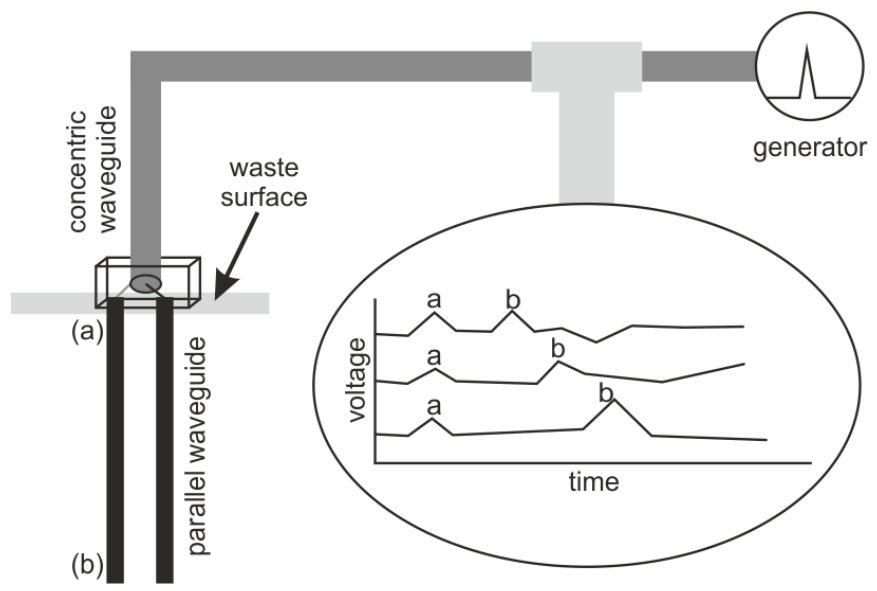

Fig. 1. TDR measurement method scheme.

\section{The aim of the work}

The aim of this paper is to validate the use of the time-domain reflectometry (TDR) method to measure soil temperature and humidity, and to explain the limits of TDR method for long-term moisture and temperature measurements in field conditions.

\section{Material and methods}

The research presented in this article was carried out in an experimental field of the University of Agriculture in Krakow. The soil used for the study is brown soil produced from Jurassic limestone. Three TDR probes were placed in an experimental field at a depth of $0.3 \mathrm{~m}$. The probes were pre-conditioned in a thermostat, in a $0.1 \mathrm{n} \mathrm{KCl}$ solution and $30^{\circ} \mathrm{C}$. Readings from the installed probes were taken every 24 hours for 30 days in June 2018. Eight respective control temperature measurements were carried out using a calibrated thermometer, and moisture was determined using the gravimetric method according to PN-Z-15008/02: 1993, with a Memmert UN55 dryer and Radwag AS.310 analytical scales. For the statistical evaluation of the results, the procedure for estimating measurement uncertainty applied in the Laboratory of Physico-Chemical and Microbiological Waste Analysis of the University of Agriculture in Krakow was used.

\section{Results}


The results of the measurements are presented in Fig. 2. Humidity measurements conducted using TDR probes and the gravimetric method demonstrate similar behavior. When analyzing humidity variation over time, both methods recorded its variability, but in the case of the TDR method, the variation is clearly non-linear. The differences between the methods can be partly explained by the periodic occurrence of air around the probes. The gravimetric method allows a very accurate moisture determination, while TDR determines local moisture in the so-called effective volume around the sensor. This phenomenon is the reason for undervaluation of the measurement results obtained with the TDR method. The standard error of TDR measurements was $0.4 \%$, with a standard deviation of $0.17 \%$ for the $95 \%$ confidence level and the coefficient $\mathrm{k}=2$. Upon measuring the surface humidity of the material, the TDR method shows no moisture accumulated in the soil's molecular structure, which is the source of the error in the presented measurements.

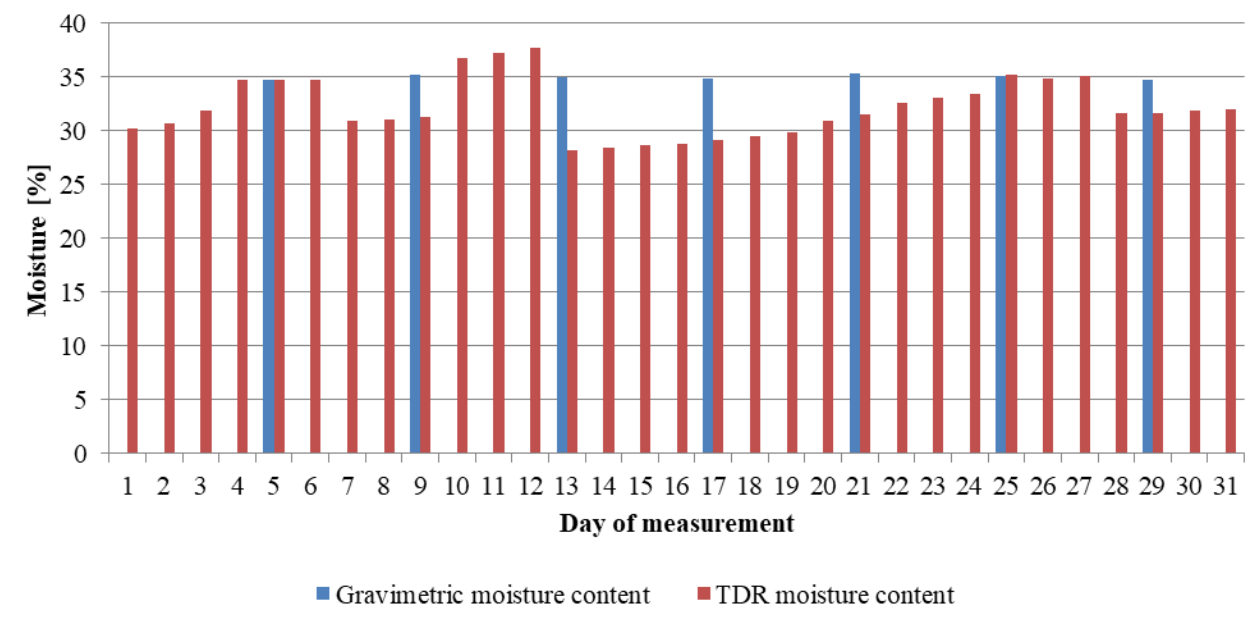

Fig. 2. Results of humidity measurements using the TDR and gravimetric methods.

The temperature measurements carried out using TDR probes and a calibrated thermometer demonstrate identical behavior (Fig. 3). Upon analyzing temperature variability over time, both methods recorded its decrease, falling within the allowable error for both methods. The differences resulting between methods can be partly explained by the different length of the measuring electrode and by the fact that the measurements were taken at points $5 \mathrm{~cm}$ apart. The standard error of temperature measurements carried out using TDR probes was $0.1 \%$ with a standard deviation of $0.17 \%$ for a $95 \%$ confidence level and a coefficient of $\mathrm{k}=2$. 


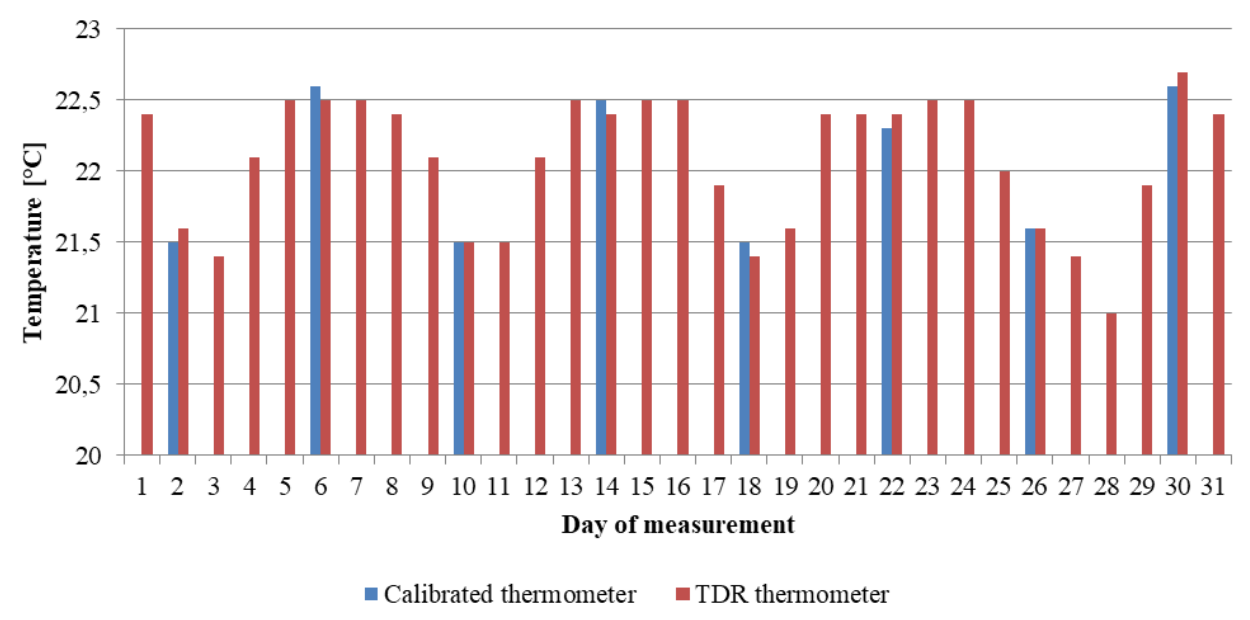

Fig. 3. Results of temperature measurements using the TDR method and a calibrated thermometer.

\section{Summary}

The article presents long-term soil moisture and temperature measurements using the TDR method and gravimetric analysis. During the tests, the proposed measurement techniques showed no signs of unreliability or technical problems. In the proposed field scale, both methods of testing humidity and temperature show a significant similarity of the obtained results. The use of the TDR also allowed not to destroy the test field, in contrast to the gravimetric method, which used a total of $10 \mathrm{~kg}$ of soil.

\section{Acknowledgements}

The publication was financed by the National Center for Research and Development as part of the strategic program "Environment, Agriculture and Forestry" BIOSTRATEG III; contract no. BIOSTRATEG3/345940/7/NCBR/2017

\section{References}

1. A.E. Latawiec, J.B. Królczyk, M. Kuboń, K. Szwedziak, A. Drosik, E. Polańczyk, K. Grotkiewicz and B.B.N. Strassbourg. Willingness to Adopt Biochar in Agriculture: The Producer's Perspective. Sustainability, 9(4), 655; doi:10.3390/su9040655. (2017)

2. M. Gliniak, W. Sobczyk. Przemysł Chemiczny 96, 2055-2059 (2017).

3. M. Gliniak, W. Sobczyk., I. Wielewska. Rocznik Ochrona Środowiska 18, 372-386 (2016).

4. M. Gliniak, W. Sobczyk. Rocznik Ochrona Środowiska, 14, 660-672 (2012).

5. Gliniak M., Trzyniec K., Jakubowski T., Lis A., Popardowski E., Wołosiewicz-Głąb M. In: Krakowiak-Bal A., Vaverkova M. (eds) Infrastructure and Environment. (Springer, Cham, 2019)

6. D. Moret, M.V. López, J.L. Arrúe. J. Hydrol. 297, 229-235 (2004).

7. D. Or, J.M. Wraith. Water Resour. Res. 35, 3399-3407 (1999). 
8. D. Moret-Fernández, J. Vicente, R. Aragüés, C. Peña, MV. López. Journal of Hydrology 448-449, 73-79 (2012).

9. J. Sikora, M. Niemiec, A. Szelag-Sikora, M. Kubon, E. Olech, and A. Marczuk, Przemysl Chem. 96, 2275-2278 (2017).

10. J. Biesaga-Kościelniak, J. Kościelniak, M. Filek, I. Marcińska, J. Krekule, I. Machackova, M. Kuboń, Acta Physiol Plant. Vol.32 No.5 pp. 987-995. (2010).

11. M. Kuboń, J. Sikora, U. Sadowska, A. Klimek-Kopyra, M. Gliniak, $19^{\text {th }}$ International Multidisciplinary Scientific Geoconference SGEM 2019, Conference proceedings Vol. 19, Eccology, Economics, Education and Legislation, Issue: 5.1, https://doi.org./10.5593/sgem2019/5.1.

12. A.A. Ponizovsky, S.M. Chudinova, Y.A. Pachepsky. J. Hydrol. 218, 35-43 (1999).

13. K. Masbruch, T.P.A. Ferré. Vadose Zone J. 2, 186-192 (2003).

14. M. Van Praagh, M. Persson, K.M. Persson. in: Proc. Sardinia 2007, 11th Int. Landfill Symp., 2007.

15. M.J. Staub, J.P. Laurent, J.P. Gourc, C. Morra. Vadose Zone J. 9, 160-171 (2009).

16. A.Szelag-Sikora, M. Niemiec, J. Sikora, Journal of Elementology, 21(3), 915-926, (2016).

17. Krótkiewicz M., Jodłowiec M., Wojtkiewicz K., Szwedziak, K. Unified process management for service and manufacture system-material resources. Advances in Intelligent Systems and Computing. (2016).

18. G. Moradi, A. Abdipour. Progr Electromag Res 77, 357-365 (2007).

19. R. Nozaki, T.K. Bose. IEEE Trans Instrum Meas 39, 945-951 (1990).

20. A. Cataldo, L. Catarinucci, L. Tarricone, F. Attivissimo, E. Piuzzi. IEEE Trans Instrum Meas 58, 3534-3543 (2009).

21. E. Piuzzi, A. Cataldo and L. Catarinucci. Measurement 42, 685-696 (2009).

22. A. Cataldo, E. Piuzzi, G. Cannazza, E. De Benedetto. J Food Eng 112, 338-345 (2012).

23. A. Cataldo, E. Piuzzi, G. Cannazza, E. De Benedetto, L. Tarricone. Measurement 43, 1031-1039 (2010).

24. A. Cataldo, E. Piuzzi, G. Cannazza, E. De Benedetto. IEEE Sens J 9, 1226-1233 (2009).

25. K.M. O'Connor, C.H. Dowding, Geomeasurements by pulsing TDR cables and probes (CRC Press 1999, UK).

26. A. Cataldo, G. Monti, E. De Benedetto, G. Cannazza, L. Tarricone. IEEE Trans Instrum Meas 58, 1420-1426 (2009).

27. S.A. Dyer, Survey of instrumentation and measurement (John Wiley \& Sons Inc 2001, USA).

28. J. Sikora, M. Niemiec, A. Szelag-Sikora, M. Kuboń, B. Mruk, A. Marczuk, Przemys1 Chemiczny, Vol. 98, Issue: 7, 1104-1107.

29. Z. Grodek-Szostak, G. Malik, D. Kajrunajtys, A. Szelag-Sikora, J. Sikora, M. Kubon, M. Niemiec, J. Kapusta-Duch, Modeling the Dependency between Extreme Prices of Selected Agricultural Products on the Derivatives Market Using the Linkage Function, Sustainability, 11(15), 4144; https://doi.org/10.3390/su11154144 (2019).

30. M. Kuboń, U. Sadowska, A. Klimek-Kopyra, J. Sikora, M. Gliniak, Impact of biochar addition on bulk density of soil, International Multidisciplinary Scientific GeoConference Surveying Geology and Mining Ecology Management, SGEM, 19(5.1), 347-354 (2019). 
31. A. Szparaga, M. Kubon, S. Kocira, E. Czerwinska, A Pawłowska, P. Hara, Z. Kobus, D. Kwasniewski, Towards Sustainable Agriculture-Agronomic and Economic Effects of Biostimulant Use in Common Bean Cultivation, Sustainability, Vol. 11 Issue: 17, DOI: 10.3390/su11174575 (2019). 